\title{
Animacy and threat in recognition memory
}

\author{
Juliana K. Leding ${ }^{1}$
}

Published online: 29 January 2020

(C) The Psychonomic Society, Inc. 2020

\begin{abstract}
Animate items are better remembered than inanimate items, suggesting that human memory has evolved to prioritize information related to survival. The proximate mechanisms for the animacy effect are not yet known, but one possibility is that animate items are more likely to capture attention, which then leads to better memory for those items. The first experiment independently manipulated the animacy and perceived threat of studied items and found that both target recognition and false-alarm recognition were higher for animate items compared to inanimate items and for threatening items compared to non-threatening items. The effects were eliminated when d' scores were calculated. The second experiment used a response signal delay (RSD) manipulation where participants were forced to respond after a short $(500 \mathrm{~ms})$ or long $(2,000 \mathrm{~ms})$ time delay during the recognition test. Similar to the first experiment, the effects of animacy and threat for target recognition and false-alarm recognition persisted and did not interact with the RSD manipulation. Taken together, the results of the studies suggest that the animacy and threat effects in memory are robust and that attention capture might be at least partly responsible for the animacy effect.
\end{abstract}

Keywords Animacy $\cdot$ Threat $\cdot$ Episodic memory $\cdot$ Recognition memory $\cdot$ Survival advantage

\section{Introduction}

The distinction between animate and inanimate items is a fundamental one (Opfer \& Gelman, 2011) that has been shown to be present even in infancy (Rakison \& Poulin-Doubis, 2001). There is evidence that humans have evolved perceptual abilities especially tuned to the detection of animate items such as predators and prey (Barrett, 2005), with priority for animals over other stimuli in both visual and attentional processing (New, Cosmides, \& Tooby, 2007). There are distinct regions of the brain devoted to processing information related to animacy (e.g., Caramazza \& Shelton, 1998; Sha et al., 2015) and recent evidence suggests that animate items are more likely to be reported in a serial visual presentation task (Guerrero \& Calvillo, 2016) and are more likely to be detected in both inattentional blindness tasks (Calvillo \& Hawkins, 2016) and change detection tasks (Altman, Khislavsky, Coverdale, \& Gilger, 2016).

In addition to the perceptual prioritization for animacy, animate items are remembered better than inanimate items, suggesting that human memory systems have evolved to

Juliana K. Leding

j.leding@unf.edu

1 Department of Psychology, 1 UNF Drive, University of North Florida, Jacksonville, FL 32224, USA prioritize information related to animacy (Nairne, VanArsdall, Pandeirada, Cogdill, \& LeBreton, 2013). The idea that animacy is prioritized in memory aligns with the adaptive memory viewpoint that human memory has evolved and adapted to better remember fitness-related information (Nairne, 2010; Nairne \& Pandeirada, 2008). For example, the survival processing advantage shows that information processed with regard to a grasslands survival scenario is better remembered than information processed in other ways (Nairne, Thompson, \& Pandeirada, 2007). In the first direct comparison of animacy in memory, after studying 12 animate and 12 inanimate words, recall was higher for animate items compared to inanimate items (Nairne et al., 2013).

The animacy effect has since been found under myriad testing conditions and with a variety of different stimuli lists (see Nairne, VanArsdall, \& Cogdill, 2017 for a review). The robustness of the animacy effect has been established but the causes of the effect are still being determined. Various proximate mechanisms have been suggested, such as valence of the items (Popp \& Serra, 2018), mental arousal or mortality salience related to animate items (Popp \& Serra, 2016), elaboration and interactive imagery (Bonin, Gelin, Laroche, Méot, \& Bugaiska, 2015; Gelin, Bugaiska, Méot, Vinter, \& Bonin, 2019; Meinhardt, Bell, Buchner, \& Röer, 2019), and the likelihood of animate items to capture attention (e.g., Bonin, Gelin, \& Bugaiska, 2014; Popp \& Serra, 2016; VanArsdall, Nairne, Pandeirada, \& Blunt, 2013). Many of these proximate 
mechanisms have been directly tested, with evidence against the role of valence in the animacy effect (Popp \& Serra, 2016) and mixed support for the role of elaboration and imagery in the animacy effect (Bonin et al., 2015; Gelin et al., 2019; Meinhardt et al., 2019).

Many recent studies suggest that attention capture might be at least partially responsible for the animacy effect. Examinations within the context of the survival processing effect have shown evidence for the persistence of the animacy effect (Gelin, Bugaiska, Méot, \& Bonin, 2017; Leding, 2018), with animate items being better remembered than inanimate items, including the survival grasslands condition that has been repeatedly shown to enhance memory (e.g., Nairne et al., 2007). That the animacy effect persists through the survival processing manipulation suggests there is a characteristic of those items that makes them more memorable even when all items are processed in a way that increases memory. Similarly, the animacy effect persisted through a shallow processing condition where participants focused on surface characteristics of the stimuli and a deep processing condition where participants focused on the semantic meaning of the stimuli (Leding, 2018). That the effect of animacy did not interact with processing condition suggests that animate items might be capturing attention of participants, as the animacy effect persisted under conditions that should weaken and strengthen memory for all studied items.

Comparisons of intentional and incidental learning show that the animacy effect persists across both test types, with a stronger animacy effect in the incidental learning condition (Félix, Pandeirada, \& Nairne, 2019), as well as across both immediate and delayed testing sessions. In the incidental learning task, the animate items might be more likely to capture attention, leading to a larger animacy effect in this condition. In the intentional learning condition, the effect of attention capture might have been mitigated by increased attention to all list items for the later memory task, leading to a reduced animacy effect compared to the incidental learning condition (Félix et al., 2019).

In line with the idea that animacy might capture participants' attention, functional magnetic resonance imaging (fMRI) results show that animate items are processed more quickly and with stronger activity in the dorsal attention network, although the differences did not mediate the animacy effect in a memory test (Xiao, Dong, Chen, \& Xue, 2016). When looking at cognitive tasks other than memory tests, animate items showed a reporting advantage in a rapid serial visual presentation task even without a reduction of the attentional blink for the animate items (Hagen \& Laeng, 2017). In a modified Stroop task, participants took longer to identify ink color of animate words than inanimate words, suggesting that the animate items were capturing attention and prioritized in cognitive processing (Bugaiska, Grégoire, Camblats, Gelin, Méot, \& Bonin, 2019).
Animacy and threat

When considering the adaptive nature of human memory, the characteristic of threat is relevant to survival and is also related to increased attention and memory. For example, snakes and guns were detected more quickly than neutral stimuli like flowers and toasters (Blanchette, 2006; Fox, Griggs, \& Mouchlianitis, 2007). Eye-tracking technology shows that participants were faster at locating threatening targets (i.e., snakes or lions) when they were presented in a stimulus display with seven non-threatening stimuli (i.e., lizards or impalas) compared to locating nonthreatening targets when they were presented in a stimulus display with seven threatening stimuli (Yorzinski, Penkunas, Platt, \& Coss, 2014).

In studies examining threat and memory, the strength of the survival processing advantage was directly related to the strength of the perceived threat in both the traditional survival grasslands scenario and a modern-day survival scenario (Olds, Lanska, \& Westerman, 2014), with better memory in the scenarios that were perceived as more threatening. Similarly, studies examining the survival processing advantage using the traditional grasslands survival scenario found comparable memory advantages for a scenario including the threat of a supernatural predator of a demon (Kazanas \& Altarriba, 2017) and better memory performance for a scenario including the threat of zombies (Soderstrom \& McCabe, 2011). Further, recognition memory was better for threatening stimuli of snakes when compared to non-threatening stimuli of fish, and better for threatening fish (e.g., sharks, morays) when compared to non-threatening, harmless snakes (Meyer, Bell, \& Buchner, 2015).

Because threatening items are more likely to capture attention and because animate stimuli often include items that would be perceived as threatening, the independent manipulation of animacy and threat was recently explored in the animacy effect. A norming study was conducted to create a list of animate and inanimate objects that were classified as either threatening or non-threatening (Leding, 2019a). In several experiments testing recall memory, the animacy effect persisted across both threatening and non-threatening items, suggesting the animacy effect in memory does not rely on the perceived threat of animate items (Leding, 2019a, 2019b). There was also an effect of threat such that threatening items were recalled more often than non-threatening items. To examine the relation of these effects to attention, directly dividing attention of participants at study led to an overall decrease in recall for all item types when compared to participants in a full attention condition, but the animacy effect and threat effect persisted across both attention conditions (Leding, 2019a). These results suggest that both animacy and perceived threat are characteristics that lead to increased memory and that the likelihood of these items to capture attention could be 
at least partly responsible for the animacy effect and threat effect in memory.

The purpose of the present studies was to extend the results in Leding (2019a, 2019b) by utilizing recognition memory paradigms to further explore the possible role of attention capture in the animacy effect and threat effect. Using a recognition memory paradigm, as opposed to a recall memory paradigm, allows for exploration of both true and false recognition rates of the various item types, allowing for further examination of the memory processes related to these effects. Because of past findings indicating that threatening items are more likely to capture attention (e.g., Blanchette, 2006; Fox et al., 2007; Yorzinski et al., 2014) and more likely to be remembered (e.g., Leding 2019a, 2019b; Meyer et al., 2015) than non-threatening items, the independent manipulation of animacy and threat allows for an examination of the animacy effect in memory without a potential confound of threat. Further, if the animacy effect persists in recognition memory for non-threatening items, this is additional evidence that the variable of perceived threat is not responsible for the animacy effect in memory.

The first experiment was designed to determine if the animacy effect and threat effect in recall memory from Leding (2019a, 2019b) would extend to recognition memory and to determine if the increases in target recognition for animacy and threat would extend to increases in false recognition for those item types. If animate items and threatening items are more likely to capture attention, then they would be likely to capture attention during the study portion of the experiment, which would lead to increased target recognition, similar to the results in tests of free recall (e.g., Leding, 2019a). There could also be a greater likelihood of false recognition for non-presented animate and threatening stimuli. This prediction follows research conducted in the survival processing literature showing that false memories are more likely in survival conditions compared to control conditions (Howe \& Derbish, 2010; Otgaar \& Smeets, 2010). It was suggested that processing survival-related information might lead to spreading activation to other survival-related knowledge and that knowledge "can be used to direct attention to key aspects of the environment that may be essential to survival. That memory can prime attention making the individual hyper-vigilant to other survival-relevant stimuli in the environment may be extremely adaptive and help the individual to detect things in the environment that might save their life" (Howe \& Derbish, p. 264). Thus, activation of the survivalrelated animate and threatening items during the study portion of the experiment might lead to spreading activation for related information and therefore an increase in false recognition for those item types.

The animacy effect has been found in recognition memory for word stimuli with no corresponding increase in false recognition for animate compared to inanimate items (Bonin et al., 2014). Bonin et al. included an incidental memory test that followed a task where participants categorized the items as being either animate or inanimate. They also included a Remember-Know-Guess (RKG) procedure where participants were instructed to respond "Remember" if the word elicited a specific memory of its presentation during the study portion and respond "Know" if the participant was confident the word was presented without a specific recollection of its presentation. These methodological differences could affect the likelihood that a difference in false recognition for animate and inanimate items would be detected.

The second experiment was designed to extend the results of the first study by including a manipulation of item presentation, with some items presented once and other items presented three times. Although the proximate mechanisms of the animacy effect are still unknown, because animate items are more likely to be recalled (e.g., Nairne et al., 2013), it seems that the memory trace for animate items might be stronger than it is for inanimate items. Thus, the repeated presentation of items at study was included to determine if the magnitude of the animacy effect would be affected by manipulating the potential strength of the memory trace of both the animate and inanimate items. It could be that repeated presentation of animate items makes them even more likely be remembered compared to inanimate items, increasing the magnitude of the animacy effect. Alternatively, it could be that the advantage for animate items is reduced or eliminated when the strength of the memory trace for inanimate items is increased. The second experiment also included a between-subjects manipulation of response signal delay (RSD) where some participants were in a short RSD condition and had to respond within $500 \mathrm{~ms}$ of stimulus presentation and other participants were in a long RSD condition and had to respond within 2,000 ms of stimulus presentation. This manipulation was included to explore whether participants can engage in more controlled and stringent source monitoring (as in the longer RSD condition) compared to faster, more automatic responding in the short RSD condition. If the animacy effect and threat effect for target recognition are related to attention capture, then the effects should persist across both RSD conditions.

\section{Experiment 1}

\section{Method}

Participants Participants were 105 students (80 and 25 indicated their current gender identity was female and male, respectively; mean age 20.80 years, $S D=3.36$ ). A power analysis using the repeated-measures, within factors for ANOVAs function in $\mathrm{G}^{*}$ Power suggested that a sample of 99 was necessary to obtain a power of .95 , with $\alpha=.05$, and an effect size 
of $\eta_{\mathrm{p}}{ }^{2}=.12$ for each of the two repeated-measures independent variables (Faul, Erdfelder, Lang, \& Buchner, 2007). ${ }^{1}$ Participants were recruited through an online experiment sign-up system and were told that they should participate if English was their first language. Seven participants indicated that English was not their first language. Analyses with and without these participants revealed the same pattern of results. The data from these participants were included in the following analyses.

Materials The stimuli list contained 112 words that were equally divided into four item types: animate threatening, animate non-threatening, inanimate threatening, and inanimate non-threatening. The words in the four item types were equated on the characteristics of familiarity, imagery, length, and frequency, and were significantly different in terms of the characteristic of threat for the threatening and nonthreatening items (Leding, 2019a). Direct RT (Jarvis, 2014, Version 2014.1.114) programs presented 56 stimuli words for 2,000 ms each with no interstimulus interval other than the screen refresh time. The words were presented in light blue font centered on a black screen. Four random presentation orders were created and participants viewed one of these four orders; the old and new items were counterbalanced across participants. An equal number of the four item types were presented to participants during the study portion. During the recognition test all 112 words were randomly presented to participants along with an image that said "Old" on the left side of the screen and "New" on the right side of the screen to remind participants of which keys they should use to respond.

Procedure Participants entered the lab individually or in groups of up to four people. They sat at computers that were separated by dividers and were given the informed consent form. After listening to instructions that they would be viewing a list of words for a later memory test, the participants viewed the 56 study words. The participants then completed a 2-min distractor task where they wrote down as many of the states in the USA as they could. Participants then listened to instructions for the memory test, which indicated that they would be presented with words and they should indicate whether the word was "old" and one that they had previously studied or whether the word was "new" and one that they had not previously studied. The " $\mathrm{z}$ " key was labeled old and the " " key was labeled new. Participants completed the 112-item

\footnotetext{
${ }^{1}$ The effect size of $\eta_{\mathrm{p}}{ }^{2}=.12$ was chosen because of effect sizes reported in four studies in Leding (2019a, 2019b). Effect sizes ranged from $\eta_{\mathrm{p}}{ }^{2}=.280$ .521 and $\eta_{\mathrm{p}}{ }^{2}=.210-.444$ for the main effects of animacy and threat, respectively. Further, in Leding (2019b) the Animacy by Threat interaction was significant in one sample, with $\eta_{\mathrm{p}}{ }^{2}=.156$. When the data from the two samples in that paper were combined, the effect size for the interaction was $\eta_{\mathrm{p}}{ }^{2}$ $=.073$. Thus, $\eta_{\mathrm{p}}{ }^{2}=.12$ was used as it was between the two smallest effects sizes reported in those studies.
}

recognition test at their own pace. When everyone was finished they were given a short demographic questionnaire that asked their age, whether English was their native language, and their current gender identity.

\section{Results}

The purpose of the present study was to examine the effects of animacy and threat in recognition memory. The proportion of target recognition, false recognition, and d' scores were analyzed. Five participants had negative overall accuracy scores (range -5 to -32 ), suggesting they misunderstood the directions for the recognition test. The data from these participants were excluded from the analyses. The three dependent variables were analyzed with 2(Animacy: Animate, Inanimate) $\times$ 2(Threat: Threatening, Non-threatening) repeated-measures ANOVAs. Table 1 includes means and standard deviations for the dependent variables for Experiment 1.

In addition to the $2 \times 2$ ANOVAs, Bayesian analyses were conducted using JASP (Version 0.10, JASP Team, 2019). The Bayes factors are included as additional evidence in support of the alternative and null hypotheses in the analyses. For Bayesian ANOVAs JASP provides inclusion Bayes factors, denoted as $B F_{\text {Inclusion, }}$, which quantify the strength of the evidence of a particular effect that is averaged across models that include the effect (Rouder, Morey, Verhagen, Swagman, \& Wagenmakers, 2017; Schulze, James, Koehler, \& Newell, 2019). For Bayesian $t$-tests, Bayes factors (denoted as $B F_{10}$ ) that quantify the strength of the evidence in favor of the alternative hypothesis are presented, where $B F_{10}<1$ indicates support for the null hypothesis and $B F_{10}>1$ indicates support for the alternative hypothesis. A $B F_{10}$ between 3 and 20 is conventionally considered as positive evidence for the alternative hypothesis, 20 to 150 as strong evidence, and greater than 150 as very strong evidence (Kass \& Raftery, 1995). Further, a $B F_{10}$ between 0.33 and 0.05 is considered as positive evidence for the null hypothesis, between 0.05 to 0.0067 as strong evidence for the null hypothesis, and $B F_{10}<.0067$ as very strong evidence for the null hypothesis.

Target recognition A 2(Animacy: Animate, Inanimate) $\times$ 2(Threat: Threatening, Non-threatening) repeated-measures ANOVA was conducted on the proportion of correctly recognized targets. There was a significant effect of animacy, $F(1$, 99) $=10.84, M S E=.02, p=.001, \eta_{\mathrm{p}}^{2}=.099, B F_{\text {Inclusion }}=$ 37.75 , with animate items being correctly recognized more often than inanimate items. There was also a significant effect of threat, $F(1,99)=11.69, M S E=.01, p=.001, \eta_{\mathrm{p}}{ }^{2}=.106$, $B F_{\text {Inclusion }}=22.55$, with threatening items being correctly recognized more often than non-threatening items. The animacyby-threat interaction was significant, $F(1,99)=4.42, M S E=$ $.02, p=.038, \eta_{\mathrm{p}}{ }^{2}=.04, B F_{\text {Inclusion }}=4.61$. The interaction was explored by comparing the recognition rate for animate and 
Table 1 Target recognition proportion, false-alarm proportion, and d' scores for Experiment 1

\begin{tabular}{|c|c|c|c|c|}
\hline & \multicolumn{2}{|l|}{ Animate } & \multicolumn{2}{|l|}{ Inanimate } \\
\hline & Threatening & $\begin{array}{l}\text { Non- } \\
\text { threatening }\end{array}$ & Threatening & $\begin{array}{l}\text { Non- } \\
\text { threatening }\end{array}$ \\
\hline Target Recognition & $.78(.14)$ & $.77(.17)$ & $.77(.16)$ & $.70(.18)$ \\
\hline False Alarm & $.25(.18)$ & $.21(.19)$ & $.23(.17)$ & $.19(.14)$ \\
\hline $\mathrm{d}^{\prime}$ & $1.65(.72)$ & $1.76(.89)$ & $1.66(.82)$ & $1.59(.72)$ \\
\hline
\end{tabular}

Note. Standard deviations are presented in parentheses

inanimate items for the threatening and non-threatening items separately. For the threatening items, there was no significant difference in recognition for the animate and inanimate items, $t(99)=0.89, p=.373, B F_{10}=0.16$. For the non-threatening items, the difference was significant, $t(99)=3.79, p<.001, d$ $=.379, B F_{10}=75.89$, with animate items having higher recognition rates than inanimate items. These results replicate Bonin et al. (2014), showing the animacy effect in recognition memory. The results also replicate Leding (2019a, 2019b), showing better memory for animate than inanimate items and better memory for threatening than non-threatening items.

False alarm recognition and $\mathbf{d}^{\prime}$ scores Howe and Derbish (2010) suggested that the activation of survival-related information could lead to spreading activation for related material, and thus increased false memories for survival-related information. If this is the case, participants might have different false recognition rates for the various item types. A 2(Animacy: Animate, Inanimate) $\times$ 2(Threat: Threatening, Non-threatening) repeated-measures ANOVA was conducted on the proportion of false alarms. The main effect of animacy and the interaction were not significant (both $p s>.206$, both $\left.B F_{\text {Inclusion }}<0.27\right)$. The main effect of threat was significant, $F(1,99)=13.26, M S E=.01, p<.001, \eta_{\mathrm{p}}{ }^{2}=.118, B F_{\text {Inclusion }}=$ 12.28; false alarms for threatening items were higher than for non-threatening items. Although false alarms for animate items were higher than for inanimate items, the effect was not significant.

To corroborate these results, d' scores were calculated for the four item types and a 2(Animacy: Animate, Inanimate) $\times$ 2(Threat: Threatening, Non-threatening) repeated-measures ANOVA was conducted on the d' scores. ${ }^{2}$ The d' scores indicate the ability to discriminate between old and new items (Snodgrass \& Corwin, 1988). The analyses on d' indicated that the main effect of animacy and the main effect of threat were not significant, $F(1,99)=1.92, M S E=.36, p=.169$, $B F_{\text {Inclusion }}=0.23$, and $F(1,99)=0.16, M S E=.27, p=.691$,

\footnotetext{
$\overline{2}$ Target recognition proportions of 1.0 were corrected using $(1-(1 / 2 \mathrm{~N}))$ where $\mathrm{N}$ was the number of targets. False recognition proportions of 0 were corrected using $(1 /(2 \mathrm{~N}))$ where $\mathrm{N}$ was the maximum number of false alarms (Macmillan \& Kaplan, 1985).
}

$B F_{\text {Inclusion }}=0.09$, respectively. The interaction was not significant, $F(1,99)=2.82, M S E=.30, p=.097, B F_{\text {Inclusion }}=.05$. These results reveal that there were no differences in discriminability for the various item types.

The results of the first experiment complement those that have been found on the animacy effect in recall memory (e.g., Nairne et al., 2013), with increased target recognition for animate items. The results also replicate more recent results suggesting that threatening items are more likely to be remembered than non-threatening items (e.g., Leding, 2019a). The use of a recognition memory test allows for closer examination of the memory processes involved in the animacy effect, including calculations of false-alarm rates and discriminability. Analyses of d' scores indicated the effects of animacy and threat were eliminated when accounting for false-alarm rates for these item types, suggesting that participants have lower discriminability for the animate and threatening items during the recognition test. These findings align with previous research in the survival processing literature showing increased false memories for survival-relevant conditions (Howe \& Derbish, 2010; Otgaar \& Smeets, 2010). These findings contrast with those found in Bonin et al. (2014), who found no difference in false-alarm rates for animate and inanimate items. There are several differences between Bonin et al. and the present study that could account for the differing results regarding false-alarm rates. First, Bonin et al. employed an incidental memory test where participants were first asked to categorize whether the presented items were animate or inanimate, whereas the present study utilized an intentional memory test with no categorization task. The categorization task could have led to more perceptual, contextual, and semantic processing of the studied items, leading to more accurate source monitoring for studied items. Second, Bonin et al. utilized the RKG procedure where participants completed the memory test aloud and for each item recognized they were to evaluate their memory trace. Completing this procedure out loud in front of an experimenter, as opposed to completing the recognition test on a computer, could cause participants to be more conservative in their responses and use more stringent criteria when making source judgments. This could reduce overall false-alarm rates and make it more difficult to detect differences between item types. When comparing the 
proportion of false-alarm rates for animate and inanimate items in Bonin et al. (.144 for animate items and .145 for inanimate items) to the marginal means for false alarms of animate and inanimate items in the present study (.228 for animate items and .209 for inanimate items) it does appear that, overall, participants in Bonin et al. were more conservative. In addition, the sample size in Bonin et al. was smaller than in the present study, which would make the detection of small effects and the interpretation of null effects more difficult. Thus, the results of the present study complement the Bonin et al. study in corroborating the animacy effect in recognition memory.

When considering the potential proximate mechanism of attention capture and its relation to the animacy effect and threat effect, it could be that animate items and threatening items are capturing the attention of participants during the study portion of the experiment and that this leads to improved target recognition for these items on the memory test, as has been shown in studies using recall (e.g., Bonin et al., 2014; Leding, 2019a; Nairne et al., 2013). However, this improved recognition for studied animate and threatening items is tied to increased false recognition for the non-studied animate and threatening items, eliminating a memory advantage for items with an animate or threatening status.

\section{Experiment 2}

The second experiment was designed to further explore the effects of animacy and threat in recognition memory, including the increased false-alarm rates for animate items and threatening items. Items were studied once or three times. Participants then completed a recognition memory test that was conducted using a between-subjects response signal delay (RSD) manipulation where participants responded under a short or longer time constraint. If attention capture is playing a role in the animacy and threat effects, then the effects should persist across the manipulations of item presentation and RSD.

\section{Method}

Participants Participants were 114 students (91 indicated their current gender identity was female, 22 indicated their current gender identity was male, and one indicated their current gender identity was non-binary trans-identity; mean age 20.63 years, $S D=4.74)$. A power analysis using the repeated-measures, between factors for ANOVAs function in $G *$ Power suggested a total sample of 100 was necessary to obtain a power of .95 , with $\alpha=.05$, with two groups, and an effect size of $\eta_{\mathrm{p}}{ }^{2}=.12$ (Faul et al., 2007). Participants were recruited through an online experiment sign-up system and were told that they should only participate if English was their first language. Seven participants indicated that English was not their first language. Analyses with and without these participants revealed the same pattern of results for the main effects of the analyses. The data from these participants were included in the following analyses.

Materials The stimuli list included the 112 words from Experiment 1. Each participant studied 56 words and the remaining 56 words were used as new items in the recognition test. The 56 studied words were composed of 14 words for each of the four item types. Further, the 14 words for each item type were split so that seven words were presented once and seven were presented three times. The presentations were counterbalanced so that all 112 stimuli served as items studied once, studied three times, and new items for different participants. Direct RT (Jarvis, 2014, Version 2014.1.114) programs included a training block for the RSD procedure and then presented the stimuli at a rate of words for $2,000 \mathrm{~ms}$ each with no interstimulus interval other than the screen refresh time. Words were centered on a black background in light blue font in a random order for each participant. The programs then included the 112-item RSD recognition test.

Procedure Participants entered the lab individually or in groups of up to four people and sat at computers separated by dividers. After informed consent, the experimenter read instructions to the participants while they followed along on the computer. The instructions stated that participants would view words and that their memory for the words would be tested. The participants completed a 30-item training block for the RSD procedure. Each trial began with a 500-ms fixation point (i.e., plus sign) followed by a test word of "yes" or "no" that was presented for $500 \mathrm{~ms}$ (short RSD condition) or 2,000 ms (long RSD condition), followed by a response signal (i.e., row of asterisks) indicating that it was time to give a response. Participants were instructed to press the key labeled "yes" (the "z" key) if the word was "yes" or the key labeled "no" (the "/" key) if the word was "no" as soon as the response signal appeared. Responses were not recorded until the response signal was presented and responses more than $500 \mathrm{~ms}$ after the response signal were given feedback stating "Too Slow." After the training block participants were reminded that they would view the study list without making responses. After the study lists, instructions for the memory test were given, which stated to respond "Yes" if they had previously studied the word and "No" if they had not previously studied the word. Participants then completed the recognition test and answered demographic questions. 
Table 2 Target recognition proportion, false alarm proportion, and d' scores for Experiment 2

\begin{tabular}{|c|c|c|c|c|}
\hline & \multicolumn{2}{|l|}{ Animate } & \multicolumn{2}{|l|}{ Inanimate } \\
\hline & Threatening & $\begin{array}{l}\text { Non- } \\
\text { threatening }\end{array}$ & Threatening & $\begin{array}{l}\text { Non- } \\
\text { threatening }\end{array}$ \\
\hline \multicolumn{5}{|l|}{ Target Recognition } \\
\hline Short RSD - Once & $.62(.22)$ & $.62(.22)$ & $.66(.21)$ & $.53(.24)$ \\
\hline Short RSD - Thrice & $.87(.15)$ & $.83(.18)$ & $.83(.15)$ & $.81(.19)$ \\
\hline Long RSD - Once & $.71(.17)$ & $.69(.21)$ & $.71(.20)$ & $.66(.23)$ \\
\hline Long RSD - Thrice & $.90(.12)$ & $.88(.14)$ & $.88(.14)$ & $.86(.17)$ \\
\hline \multicolumn{5}{|l|}{ False Alarm } \\
\hline Short RSD & $.22(.15)$ & $.18(.17)$ & $.16(.18)$ & $.18(.16)$ \\
\hline Long RSD & $.15(.12)$ & $.11(.13)$ & $.10(.08)$ & $.08(.10)$ \\
\hline \multicolumn{5}{|l|}{$\mathrm{d}^{\prime}$} \\
\hline Short RSD - Once & $1.22(.76)$ & $1.37(.87)$ & $1.59(.95)$ & $1.14(.86)$ \\
\hline Short RSD - Thrice & $1.96(.76)$ & $2.00(.93)$ & $2.07(.83)$ & $1.94(.95)$ \\
\hline Long RSD - Once & $1.73(.71)$ & $1.88(.81)$ & $1.93(.77)$ & $1.87(.76)$ \\
\hline Long RSD - Thrice & $2.31(.59)$ & $2.42(.63)$ & $2.43(.62)$ & $2.45(.63)$ \\
\hline
\end{tabular}

Note. Standard deviations are presented in parentheses

\section{Results}

Data from one participant with a negative overall accuracy score were removed. Table 2 includes means and standard deviations for the remaining 113 participants for target recognition, false alarms, and d' scores. Missing data from slow responses constituted $6.87 \%$ and $4.78 \%$ in the short and long conditions, respectively, as in other RSD studies (e.g., Wong \& Rotello, 2010).

Target recognition A 2(Animacy: Animate, Inanimate) $\times$ 2(Threat: Threatening, Non-threatening) $\times 2$ (Presentations: One Presentation, Three Presentations) $\times 2$ (RSD: Long, Short) mixed-factors ANOVA was conducted on the proportion of target items recognized. Animacy, threat, and presentations were within-subjects variables and RSD was a between-subjects variable. The main effect of RSD was significant, $F(1,111)=10.02, M S E=.10, p=.002, \eta_{\mathrm{p}}{ }^{2}=.083$, $B F_{\text {Inclusion }}=3.29$, with higher recognition in the long condition than in the short condition. The main effect of threat was significant, $F(1,111)=10.89, M S E=.03, p=.001, \eta_{\mathrm{p}}{ }^{2}=.089$, $B F_{\text {Inclusion }}=8.89$, with higher recognition for threatening items than non-threatening items and the main effect of presentations was significant, $F(1,111)=321.10, M S E=.03, p<$ $.001, \eta_{\mathrm{p}}{ }^{2}=.743, B F_{\text {Inclusion }}>100,000$, with items presented three times recognized more often than items presented once. Animate items were recognized more often than inanimate items, but the main effect of animacy was not significant, $F(1,111)=3.15, M S E=.03, p=.079, B F_{\text {Inclusion }}=0.11$. The only interaction that was significant was the animacy $\times$ threat $\times$ presentations interaction, $F(1,111)=5.69, M S E=.02$, $p=.019, \eta_{\mathrm{p}}^{2}=.049, B F_{\text {Inclusion }}=0.02$.
The significant interaction was further explored with 2(Animacy: Animate, Inanimate) $\times$ 2(Threat: Threatening, Non-threatening) repeated-measures ANOVAs conducted separately on the proportion of target items recognized for items presented once and items presented three times. For the items presented once, the main effect of threat was significant, $F(1,112)=7.55, M S E=.04, p=.007, \eta_{\mathrm{p}}{ }^{2}=.063$, $B F_{\text {Inclusion }}=4.62$, with higher recognition for the threatening items than the non-threatening items. The main effect of animacy was not significant, $F(1,112)=0.88, M S E=.03, p$ $=.349, B F_{\text {Inclusion }}=0.30$. The animacy by threat interaction was significant, $F(1,112)=6.53, M S E=.03, p=.012, \eta_{\mathrm{p}}{ }^{2}=$ $.055, B F_{\text {Inclusion }}=1.04$. This interaction was further explored by comparing recognition for animate and inanimate items for the threatening and non-threatening items separately. There was no significant difference in animacy for threatening items presented once, $t(112)=1.08, p=.284, B F_{10}=0.18$, but there was a significant difference in animacy for non-threatening items presented once, $t(112)=2.47, p=.015, d=.23, B F_{10}$ $=1.90$, with higher recognition for non-threatening animate items than non-threatening inanimate items. Thus, the results for the items studied once extend those found in the first experiment, in that a significant interaction between animacy and threat occurred showing that threatening items are recognized more often than non-threatening items and that there is a significant effect of animacy when comparing the nonthreatening items but not when comparing the threatening items. These effects persisted across the RSD manipulation.

For the items presented three times, there was a significant main effect of animacy, $F(1,112)=3.92, M S E=.02, p=.050$, $\eta_{\mathrm{p}}{ }^{2}=.034, B F_{\text {Inclusion }}=0.50$, with animate items recognized more often than inanimate items. There was a significant main 
effect of threat, $F(1,112)=4.52, M S E=.02, p=.036, \eta_{\mathrm{p}}{ }^{2}=$ $.039, B F_{\text {Inclusion }}=0.86$, with threatening items recognized more often than non-threatening items. The interaction was not significant, $F(1,112)=0.19, M S E=.02, p=.664$, $B F_{\text {Inclusion }}=0.14$. These significant effects for the items presented three times suggest that the effects of animacy and threat are robust because memory strength for all of the item types should have been strong, which could have eliminated the advantage found for animate and threatening items, and yet the main effects persisted. As for the items presented one time, the effects persisted across both RSD conditions.

False alarm recognition and d' scores A 2(Animacy: Animate, Inanimate $) \times 2$ (Threat: Threatening, Non-threatening $) \times$ 2(RSD: Long, Short) mixed-factors ANOVA was conducted on the proportion of false alarms. The main effect of animacy was significant, $F(1,111)=15.76, M S E=.01, p<.001, \eta_{\mathrm{p}}{ }^{2}=$ $.124, B F_{\text {Inclusion }}=40.09$, with more false alarms for animate than inanimate items. The main effect of threat was significant, $F(1,111)=5.14, M S E=.01, p=.025, \eta_{\mathrm{p}}{ }^{2}=.044$, $B F_{\text {Inclusion }}=1.79$, with more false alarms for threatening items than non-threatening items. The main effect of RSD was also significant, $F(1,111)=11.65, M S E=.05, p=.001, \eta_{\mathrm{p}}{ }^{2}=.095$, $B F_{\text {Inclusion }}=17.78$, with more false alarms in the short condition compared to the long condition. The only significant interaction was the animacy $\times$ threat interaction, $F(1,111)=$ $4.58, M S E=.01, p=.035, \eta_{\mathrm{p}}{ }^{2}=.040, B F_{\text {Inclusion }}=2.45$, which was further explored by conducting paired-samples $t$-tests comparing animate and inanimate false-alarm rates for the threatening and non-threatening items separately. For the threatening items, there was a significant difference in falsealarm rates, $t(112)=3.98, p<.001, d=0.38, B F_{10}=147.03$, with more false alarms for animate items than inanimate items. For the non-threatening items, there was no significant difference in false-alarm rates for animate and inanimate items, $t(112)=1.06, p=.291, B F_{10}=0.18$. These results suggest that not only do participants have increased target recognition for animate and threatening items compared to inanimate and non-threatening items, but they are also more likely to experience false alarms for these items.

To corroborate these results, d' scores were analyzed with a 2(Animacy: Animate, Inanimate) $\times 2$ (Threat: Threatening, Non-threatening) $\times 2$ (Presentations: One Presentation, Three Presentations $) \times 2$ (RSD: Long, Short) mixed-factors ANOVA. The main effects of animacy and threat were not significant, $F(1,111)=2.24, M S E=.44, p=.137, B F_{\text {Inclusion }}=.26$, and $F(1,111)=0.13, M S E=.58, p=.717, B F_{\text {Inclusion }}=.20$, respectively. The main effect of presentations and the main effect of RSD were both significant, $F(1,111)=332.74$, $M S E=.25, p<.001, \eta_{\mathrm{p}}{ }^{2}=.750, B F_{\text {Inclusion }}>100,000$, and $F(1,111)=19.53, M S E=2.55, p<.001, \eta_{\mathrm{p}}{ }^{2}=.150$, $B F_{\text {Inclusion }}=165.04$, respectively. The d' scores were higher for items presented three times compared to items presented once and higher in the long RSD condition compared to the short RSD condition. The only interactions that were significant were the animacy $\times$ threat interaction, $F(1,111)=8.15$, $M S E=.50, p=.005, \eta_{\mathrm{p}}{ }^{2}=.068, B F_{\text {Inclusion }}=1.16$, and the animacy $\times$ threat $\times$ presentations interaction, $F(1,111)=5.76$, $p=.018, \eta_{\mathrm{p}}^{2}=.049, B F_{\text {Inclusion }}=.03$.

The interactions were further explored with 2(Animacy: Animate, Inanimate) $\times 2$ (Threat: Threatening, Non-threatening) repeated-measures ANOVAs conducted separately for the items presented one time and three times. For items presented once, the only significant effect was the animacy by threat interaction, $F(1,112)=11.04, M S E=.41, p=.001, \eta_{\mathrm{p}}{ }^{2}$ $=.090, B F_{\text {Inclusion }}=2.22$, which was further explored by conducting paired-samples $t$-tests comparing d' scores of animate and inanimate items for the threatening and nonthreatening items separately. For threatening items, there was a significant difference in d' scores for animate and inanimate items, $t(112)=3.46, p=.001, d=.33, B F_{10}=26.94$, where d' scores were higher for inanimate threatening items compared to animate threatening items. Thus, the high rate of false alarms for animate threatening items led to a reversal of the animacy effect for the d' scores for items presented once. For non-threatening items, the effect of animacy was not significant, $t(112)=1.38, p=.171, B F_{10}=.26$.

For the items presented three times, there was no significant effect of animacy, $F(1,112)=1.12, M S E=.24, p=.293$, $B F_{\text {Inclusion }}=.11$, or threat, $F(1,112)=0.05, M S E=.32, p=$ $.833, B F_{\text {Inclusion }}=.07$. The interaction was also not significant, $F(1,112)=1.67, M S E=.28, p=.199, B F_{\text {Inclusion }}=.02$. Thus, similar to Experiment 1, when false-alarm rates were accounted for the effects of animacy and threat disappeared. The null effects are further corroborated by the Bayes factors that provide support for the null hypothesis. Further, for the threatening items presented once, the animacy effect reversed, with d' scores being higher for the inanimate items. Taken together with the results of Experiment 1, these results suggest that animate items and threatening items might be more likely to capture attention during encoding, which leads to increased target recognition for the items. The increased attention to these items during encoding might lead to spreading activation of similar, but unpresented, information such that animate and threatening items are then more likely to be falsely recognized. These results are similar to those of Howe and Derbish (2010), who found increased false recognition for survivalrelated information.

\section{General discussion}

The effect of animacy on memory has been well established and fits within our understanding of the adaptive view that memories have evolved to prioritize information related to survival (see Nairne et al., 2017, for a review). Recent studies 
have provided increasing evidence for the robustness of the effect in that it can be seen in both intentional and incidental memory paradigms (Félix et al., 2019), across a variety of processing conditions (Gelin et al., 2017; Leding, 2018), under divided attention (Leding, 2019a), and leads to increased memory for information that has been associated with animacy (Gelin, Bonin, Méot, \& Bugaiska, 2019; Laurino \& Kaczer, 2019; VanArsdall et al., 2013).

In addition to animacy, another characteristic relevant to survival is perceived threat. Information related to higher levels of threat is more likely to be remembered (e.g., Kazanas \& Altarriba, 2017; Meyer et al., 2015; Olds et al., 2014; Soderstrom \& McCabe, 2011). When animacy and threat were independently manipulated, recall was higher for animate items compared to inanimate items and for threatening items compared to non-threatening items, with no evidence that the animacy effect in memory depended upon the perceived threat of the animate items (Leding, 2019a, 2019b). Similar independent manipulations of these variables have been utilized in examinations of animacy on other cognitive processes. For example, animacy and threat were independently manipulated in an inattentional blindness task and support for the animate-monitoring hypothesis, but not the threatmonitoring hypothesis, was found in both experiments (Calvillo \& Hawkins, 2016). The present studies were conducted to extend the generalizability of the results of the independent influence of animacy and threat on memory to recognition memory. This allowed for an examination of true recognition for the variables of animacy and threat in addition to an examination of the likelihood of false recognition for these items.

The first experiment provides corroborative evidence for the effects of animacy and threat on memory using recognition memory. Further, the use of a recognition test allows examination of false-alarm rates, which is an extension of studies examining the animacy effect using free recall. Studies examining the animacy effect on free recall typically find no difference in intrusions for animate and inanimate items (e.g., Leding, 2018) or higher rates of intrusions for inanimate than animate items (e.g., Bonin et al., 2015; Félix et al., 2019), whereas the present studies found higher rates of false recognition for animate items and threatening items. This is similar to the idea suggested by Howe and Derbish (2010) that processing survival-related information can lead to spreading activation for those concepts, leading to an increased chance of false memories for new, survival-consistent information.

Further, in the first experiment, the d' scores resulted in no significant effects for animacy or threat, suggesting that the added benefit that these items receive in terms of true recognition is eliminated when considering the likelihood that these items are also more likely to be falsely recognized. These null results were corroborated by the Bayesian analyses. There are, of course, other potential explanations for why animate and threatening items were more likely to be falsely recognized. For example, it could be that these items are less distinctive, more closely associated with each other, or more restricted within categories. ${ }^{3}$ While it is possible that there is a characteristic of the animate items and threatening items that differs compared to the inanimate and non-threatening items, the four item types were equivalent on the characteristics of imageability, concreteness, word length, and frequency (Leding, 2019a), thereby reducing the chances that certain items are more distinctive. Further, the animacy effect cannot be explained with a categorical recall strategy (VanArsdall, Nairne, Pandeirada, \& Cogdill, 2015), suggesting that it is unlikely that the animacy effect is due to items being more closely associated with each other or more restricted within categories.

The second experiment was designed to further test the robustness of the effects of animacy and threat in recognition memory by manipulating number of presentations at study and how quickly participants responded during the recognition test. Because repetition of studied items should increase the memory trace for those items, it could have led to an extinction of the animacy effect or threat effect because the increased strength of all the items studied three times could lead to near-ceiling levels of recognition. This was not the case; the animacy effect and threat effect were both significant for items presented three times. For the items presented once there was a significant interaction of animacy and threat that was due to low recognition rates of inanimate non-threatening items compared to both animate item types and the inanimate threatening items. Further, the effects of animacy and threat persisted across both RSD conditions. Although recognition scores were overall lower in the short RSD condition, the RSD manipulation did not interact with any of the other factors, showing the robustness of both the animacy effect and threat effect on memory.

The traditional analyses and Bayesian analyses on falsealarm rates and d' scores in Experiment 2 corroborated Experiment 1, suggesting that the memory advantage afforded by the animacy and threat status of items comes with the caveat that those items are more likely to be falsely recognized. These results are in line with the "more is less" concept suggested by Toglia, Neuschatz, and Goodwin (1999), where manipulations that increase target memories often lead to increases in false memories, leading to a reduction or elimination of the increased memory. This idea is like the results demonstrating that processing items with regard to the survival grasslands scenario led to an increase in true memories and false memories, with analyses conducted on net accuracy scores eliminating the survival processing advantage (Howe \& Derbish, 2010; Otgaar \& Smeets, 2010). Similarly, in the present experiments, the improvements in memory for the

\footnotetext{
${ }^{3}$ I would like to thank a reviewer for suggesting these alternative explanations.
} 
animate and threatening items were accompanied by increases in false alarms of the same item types, leading to an elimination of the effects in the d' scores.

The increase in memory inaccuracy for survival-related information, including information processed with regard to survival processing (Howe \& Derbish, 2010; Otgaar \& Smeets, 2010), survival-relevant items (Howe \& Derbish), and for animate objects and threatening objects in the current studies, could be interpreted as a disadvantage to the adaptive view of memory. If a characteristic of stimuli or the way in which stimuli are processed causes increases in accurate memories only when accompanied with increases in inaccurate memories, one might interpret this as a disadvantage. However, it is possible that illusory memories themselves could be advantageous in an evolutionary sense. As discussed by Howe and Derbish, the increase in false memories could itself be an adaptive advantage in that processing survivalrelevant information might cause greater attention to other survival-relevant information. In line with the suggestion that a proximate mechanism for the animacy effect could be attention capture of the items (e.g., Bonin et al. 2014; Popp \& Serra, 2016; VanArsdall et al., 2013), Howe and Derbish suggest that spreading activation and memory for survival-related information might prime the attention of an individual to make them hyper-vigilant to other survival-related information. That rapid activation of survival-related information might then lead to an increased opportunity for false memories for other survival-related information (Howe \& Derbish). The present studies corroborate this suggestion, as the survivalrelated characteristics of animacy and threat produced greater true and false memories, and the effects were maintained through manipulations that should affect the strength of participants' memories and their ability to make accurate and controlled source judgments. That the effects were maintained provides evidence for the idea that processing survival-related information causes an increase in participants' attention for other survival-relevant information, which can lead to both increases in true memory and, subsequently, false memory for that information.

\section{Conclusion}

The current studies support the idea from Nairne and Pandeirada (2008) that memory is constructive, often including false but relevant information, suggesting that our memory uses the past in service of the present or to predict the likelihood of future events. As Howe and Derbish (2010) suggested, the activation that occurs when processing survivalrelated information might prime individuals to attend to other survival-related information. The results of the current studies suggest that the survival-related characteristics of animacy and threat might be capturing attention of participants, and this increased attention could be one factor leading to increased memories for those items. Although attention capture was not directly manipulated, the results of the current studies add to the existing studies that build a case for the importance of attention capture in the animacy effect (e.g., Bugaiska et al., 2019; Félix et al., 2019; Gelin et al., 2017; Leding, 2019a). Future studies could further explore the role of attention capture as a potential proximate mechanism for the animacy effect by determining if certain stimuli types are more likely to capture attention of participants and if that is directly related to memory for those items. For example, Yorzinski et al. (2014) used eye-tracking technology to determine that threatening items are more quickly detected than non-threatening items. Eye-tracking technology has also shown that animate objects were more likely to be attended to and were attended to longer, when compared to inanimate objects (Yang, Wang, Yan, Zhu, Chen, \& Wang, 2012). Similar studies could use eye-tracking to determine if certain stimuli types (e.g., animate items or threatening items) are more likely to be attended to, and then use that information to determine if that attention is related to memory performance.

Open Practices Statement The data for the experiments reported here are not available and the experiments were not preregistered. The list of stimuli can be found here: https:// doi.org/10.3758/s13421-018-0873-x.

\section{References}

Altman, M.N., Khislavsky, A.L., Coverdale, M.E., \& Gilger, J.W. (2016). Adaptive attention: How preference for animacy impacts change detection. Evolution and Human Behavior, 37, 303-314. https:// doi.org/10.1016/j.evolhumbehav.2016.01.006

Barrett, H.D. (2005). Adaptations to predators and prey. In D. Buss (Ed.), The handbook of evolutionary psychology (pp. 200-223). Hoboken, NJ: John Wiley.

Blanchette, I. (2006). Snakes, spiders, guns, and syringes: How specific are evolutionary constraints on the detection of threatening stimuli? The Quarterly Journal of Experimental Psychology, 59, 1484-1504. https://doi.org/10.1080/02724980543000204

Bonin, P., Gelin, M., \& Bugaiska, A. (2014). Animates are better remembered than inanimates: Further evidence from word and picture stimuli. Memory \& Cognition, 42, 370-382. https://doi.org/10.3758/ s13421-013-0368-8

Bonin, P., Gelin, M., Laroche, B., Méot, A., \& Bugaiska, A. (2015). The "how" of animacy effects in episodic memory. Experimental Psychology, 62, 371-384. https://doi.org/10.1027/1618-3169/ a000308

Bugaiska, A., Grégoire, L., Camblats, A., Gelin, M., Méot, A., \& Bonin, P. (2019). Animacy and attentional processes: Evidence from the Stroop task. Quarterly Journal of Experimental Psychology, 72, 882-889. https://doi.org/10.1177/1747021818771514

Calvillo, D.P., \& Hawkins, W.C. (2016). Animate objects are detected more frequently than inanimate objects in inattentional blindness tasks independently of threat. Journal of General Psychology, 143, 101-115. https://doi.org/10.1080/00221309.2016.1163249 
Caramazza, A., \& Shelton, J.R. (1998). Domain-specific knowledge systems in the brain: The animate-inanimate distinction. Journal of Cognitive Neuroscience, 10, 1-34. https://doi.org/10.1162/ 089892998563752

Faul, F., Erdfelder, E., Lang, A., \& Buchner, A. (2007). GPower 3: A flexible statistical power analysis program for the social, behavioral, and biomedical sciences. Behavior Research Methods, 39, 175-191. https://doi.org/10.3758/BF03193146

Félix, S.B., Pandeirada, J.N.S., \& Nairne, J.S. (2019). Adaptive memory: Longevity and learning intentionality of the animacy effect. Journal of Cognitive Psychology. https://doi.org/10.1080/20445911.2019. 1586716

Fox, E., Griggs, L., \& Mouchlianitis, E. (2007). The detection of fearrelevant stimuli: Are guns noticed as quickly as snakes?. Emotion, 7, 691-696. https://doi.org/10.1037/1528-3542.7.4.691

Gelin, M., Bonin, P., Méot, A., \& Bugaiska, A. (2019). Do animacy effects persist in memory for context? Quarterly Journal of Experimental Psychology, 71, 965-974.

Gelin, M., Bugaiska, A., Méot, A., \& Bonin, P. (2017). Are animacy effects in episodic memory independent of encoding instructions?. Memory, 25, 2-18. https://doi.org/10.1080/09658211.2015.1117643

Gelin, M., Bugaiska, A., Méot, A., Vinter, A. \& Bonin, P. (2019). Animacy effects in episodic memory: Do imagery processes really play a role? Memory, 27, 209-223. https://doi.org/10.1080/ 09658211.2018 .1498108

Guerrero, G., \& Calvillo, D.P. (2016). Animacy increases second target reporting in a rapid serial visual presentation task. Psychonomic Bulletin \& Review, 23, 1832-1838. https://doi.org/10.3758/s13423016-1040-7

Hagen, T., \& Laeng, B. (2017). Animals do not induce or reduce attentional blinking, but they are reported more accurately in a rapid serial visual presentation task. I-Perception, 8. https://doi.org/10.1177/ 2041669517735542

Howe, M.L., \& Derbish, M.H. (2010). On the susceptibility of adaptive memory to false memory illusions. Cognition, 115, 252-267. https:// doi.org/10.1016/j.cognition.2009.12.016

Jarvis, B.G. (2014). DirectRT (Version 2014.1.114) [Computer Software]. New York, NY: Empirisoft Corporation.

JASP Team (2019). JASP (Version 0.10) [Computer software].

Kass, R.E., \& Raftery, A.E. (1995). Bayes factors. Journal of the American Statistical Association, 90, 773-795. https://doi.org/10. 1080/01621459.1995.10476572

Kazanas, S.A., \& Altarriba, J. (2017). Did our ancestors fear the unknown? The role of predation in the survival advantage. Evolutionary Behavioral Sciences, 11, 83-91. https://doi.org/10. 1037/ebs0000074

Laurino, J., \& Kaczer, L. (2019). Animacy as a memory enhancer during novel word learning: Evidence from orthographic and semantic memory tasks. Memory. https://doi.org/10.1080/09658211.2019. 1572195

Leding, J.K. (2018). The animacy advantage in memory: Manipulations of levels of processing and survival processing. The American Journal of Psychology, 131, 273-281.

Leding, J.K. (2019a). Adaptive memory: Animacy, threat, and attention in free recall. Memory \& Cognition. https://doi.org/10.3758/s13421018-0873-x

Leding, J.K. (2019b). Intentional memory and online data collection: A test of the effects of animacy and threat on episodic memory. Journal of Cognitive Psychology, 31, 4-15. https://doi.org/10.1080/ 20445911.2018.1564756

Macmillan, N.A., \& Kaplan, H.L. (1985). Detection theory analysis of group data: Estimating sensitivity from average hit and false-alarm rates. Psychological Bulletin, 98, 185-199. https://doi.org/10.1037/ 0033-2909.98.1.185

Meinhardt, M. J., Bell, R., Buchner, A., \& Röer, J. P. (2019). Adaptive memory: Is the animacy effect on memory due to richness of encoding? Journal of Experimental Psychology: Learning, Memory, and Cognition. https://doi.org/10.1037/xlm0000733

Meyer, M.M., Bell, R., \& Buchner, A. (2015). Remembering the snake in the grass: Threat enhances recognition but not source memory. Emotion, 15, 721-730. https://doi.org/10.1037/emo0000065

Nairne, J.S. (2010). Adaptive memory: Evolutionary constraints on remembering. In B.H. Ross (Ed.), The psychology of learning and motivation: Advances in research and theory., Vol. 53. (Vol. 53, pp. 1-32). San Diego, CA: Elsevier Academic Press. https://doi. org/10.1016/S0079-7421(10)53001-9

Nairne, J.S., \& Pandeirada, J.N.S. (2008). Adaptive memory: Remembering with a stone-age brain. Current Directions in Psychological Science, 17, 239-243. https://doi.org/10.1111/j. 1467-8721.2008.00582.x

Nairne, J.S., Thompson, S.R., \& Pandeirada, J.N.S. (2007). Adaptive memory: Survival processing enhances retention. Journal of Experimental Psychology: Learning, Memory, and Cognition, 33, 263-273. https://doi.org/10.1037/0278-7393.33.2.263

Nairne, J.S., VanArsdall, J.E., \& Cogdill, M. (2017). Remembering the living: Episodic memory is tuned to animacy. Current Directions in Psychological Science, 26, 22-27. https://doi.org/10.1177/ 0963721416667711

Nairne, J.S., VanArsdall, J.E., Pandeirada, J.N.S., Cogdill, M., \& LeBreton, J.M. (2013). Adaptive memory: The mnemonic value of animacy. Psychological Science, 24, 2099-2105.

New, J., Cosmides, L., \& Tooby, J. (2007). Category specific attention for animals reflects ancestral priorities, not expertise. Proceedings of the National Academy of Sciences, 104, 16598-16603. https://doi.org/ 10.1073/pnas.0703913104

Olds, J.M., Lanska, M., \& Westerman, D.L. (2014). The role of perceived threat in the survival processing memory advantage. Memory, 22, 26-35. https://doi.org/10.1080/09658211.2013.806554

Opfer, J.E., \& Gelman, S.A. (2011). Development of the animateinanimate distinction. In U. Goswami (Ed.), The Wiley-Blackwell handbook of childhood cognitive development $\left(2^{\text {nd }}\right.$ ed., pp. $213-$ 238). Oxford, England: Wiley-Blackwell.

Otgaar, H., \& Smeets, T. (2010). Adaptive memory: Survival processing increases both true and false memory in adults and children. Journal of Experimental Psychology: Learning, Memory, and Cognition, 36, 1010-1016. https://doi.org/10.1037/a0019402

Popp, E.Y., \& Serra, M.J. (2016). Adaptive memory: Animacy enhances free recall but impairs cued recall. Journal of Experimental Psychology: Learning, Memory, and Cognition, 42, 186-201. https://doi.org/10.1037/xlm0000174

Popp, E.Y., \& Serra, M.J. (2018). The animacy advantage for free recall performance is not attributable to greater mental arousal. Memory, 26, 89-95. https://doi.org/10.1080/09658211.2017.1326507

Rakison, D.H., \& Poulin-Doubis, D. (2001). The developmental origin of the animate-inanimate distinction. Psychological Bulletin, 127, 209228. https://doi.org/10.1037/0033-2909.127.2.209

Rouder, J. N., Morey, R. D., Verhagen, J., Swagman, A. R., \& Wagenmakers, E.-J. (2017). Bayesian analysis of factorial designs. Psychological Methods, 22, 304-321. https://doi.org/10.1037/ met0000057

Schulze, C., James, G., Koehler, D. J., \& Newell, B. R. (2019). Probability matching does not decrease under cognitive load: A preregistered failure to replicate. Memory \& Cognition, 47, 511518. https://doi.org/10.3758/s13421-018-0888-3

Sha, L., Haxby, J.V., Abdi, H., Guntupalli, J.S., Oosterhof, N.N., Halchenko, Y.O., \& Connolly, A.C. (2015). The animacy continuum in the human ventral vision pathway. Journal of Cognitive Neuroscience, 27, 665-678. https://doi.org/10.1162/jocn a 00733

Snodgrass, J. G., \& Corwin, J. (1988). Pragmatics of measuring recognition memory: Applications to dementia and amnesia. Journal of Experimental Psychology: General, 117, 34-50. https://doi.org/10. 1037/0096-3445.117.1.34 
Soderstrom, N.C., \& McCabe, D.P. (2011). Are survival processing memory advantages based on ancestral priorities?. Psychonomic Bulletin \& Review, 18, 564-569. https://doi.org/10.3758/s13423-011-0060-6

Toglia, M.P., Neuschatz, J.S., \& Goodwin, K.A. (1999). Recall accuracy and illusory memories: When more is less. Memory, 7, 233-256. https://doi.org/10.1080/741944069

VanArsdall, J.E., Nairne, J.S., Pandeirada, J.N.S., \& Blunt, J.R. (2013). Adaptive memory: Animacy processing produces mnemonic advantages. Experimental Psychology, 60, 172-178. https://doi.org/10. 1027/1618-3169/a000186

VanArsdall, J.E., Nairne, J.S., Pandeirada, J.S., \& Cogdill, M. (2015). Adaptive memory: Animacy effects persist in paired-associate learning. Memory, 23, 657-663. https://doi.org/10.1080/09658211.2014. 916304

Wong, M., \& Rotello, C.M. (2010). Conjunction errors and semantic transparency. Memory \& Cognition, 38, 47-56. https://doi.org/10. 3758/MC.38.1.47
Xiao, X., Dong, Q., Chen, C., \& Xue, G. (2016). Neural pattern similarity underlies the mnemonic advantages for living words. Cortex: A Journal Devoted to the Study of the Nervous System and Behavior, 79, 99-111. https://doi.org/10.1016/j.cortex.2016.03.016

Yang, J., Wang, A., Yan, M., Zhu, Z., Chen, C., \& Wang, Y. (2012). Distinct processing for pictures of animals and objects: Evidence from eye movements. Emotion, 12, 540-551. https://doi.org/10. 1037/a0026848

Yorzinski, J.L., Penkunas, M.J., Platt, M.L., \& Coss, R.G. (2014). Dangerous animals capture and maintain attention in humans. Evolutionary Psychology, 12, 534-548. https://doi.org/10.1177/ 147470491401200304

Publisher's note Springer Nature remains neutral with regard to jurisdictional claims in published maps and institutional affiliations. 